\title{
Critical illness-related corticosteroid insufficiency during difficult weaning from mechanical ventilation
}

François Bagate ${ }^{1,2^{*}}\left(\mathbb{D}\right.$, Alexandre Bedet ${ }^{1,2}$, Françoise Tomberli ${ }^{1,2}$, Florence Boissier ${ }^{1,4,5}$, Keyvan Razazi ${ }^{1,2}$, Nicolas de Prost ${ }^{1,2,3}$, Guillaume Carteaux ${ }^{1,2,3}$ and Armand Mekontso Dessap ${ }^{1,2,3}$

\begin{abstract}
Background: Critical illness-related corticosteroid insufficiency (CIRCI) is common during critical illness and is usually associated with poor outcomes, as prolonged duration of mechanical ventilation (MV) and higher mortality. CIRCI may alter cardiac and vascular functions. Weaning-induced pulmonary oedema (WiPO) is a major mechanism of weaning failure. The aim of this study was to evaluate the role of $\mathrm{CIRCl}$ in patients with difficult ventilator weaning and its possible relation with WiPO.
\end{abstract}

Methods: This is a prospective study conducted in the intensive care of a university hospital in France. Patients under MV for more than $24 \mathrm{~h}$, meeting weaning criteria and having failed the first spontaneous breathing trial (SBT) underwent a corticotropin stimulation test, with assessment of total blood cortisol levels immediately before $\left(T_{0}\right) 0.25 \mathrm{mg}$ iv of tetracosactrin and 30 and 60 min afterward. $\Delta_{\max }$ was defined as the difference between the maximal value after the test and $T_{0}$. CIRCl was defined as $T_{0}<10 \mu \mathrm{g} / \mathrm{dL}(276 \mathrm{nmol} / \mathrm{L})$ and $/ \mathrm{or} \Delta_{\max }<9 \mu \mathrm{g} / \mathrm{dL}(248 \mathrm{nmol} / \mathrm{L})$ and inadequate adrenal reserve as $\Delta_{\max }<9 \mu \mathrm{g} / \mathrm{dL}$. Biomarkers (natriuretic peptide and protidemia) sampling and echocardiograms were performed during the second SBT and were used to diagnose WiPO, which was defined according to two definitions (one liberal and one conservative) derived from recent publications on the topic. Successful extubation was defined as patient alive without reintubation 7 days after extubation. A competing risk analysis was used to assess extubation failure and mortality.

Results: Seventy-six consecutive patients ( $63 \pm 14$ years; 49 men) with difficult weaning were enrolled. $\mathrm{CIRCl}$ and inadequate adrenal reserve occurred in $25(33 \%)$ and 17 (22\%) patients, respectively. The probability of successful extubation was significantly decreased in patients with $\mathrm{CIRCI}$ or inadequate adrenal reserve, as compared to their counterparts, and this association persisted after adjustment on severity (SOFA score at first SBT). WiPO occurred in 44 (58\%) and 8 (11\%) patients, according to the liberal and conservative definition, respectively. WiPO was not associated with $\mathrm{CIRCI}$ nor with inadequate adrenal reserve.

Conclusion: $\mathrm{CIRCI}$ was common during difficult weaning and was associated with its prolongation. We did not find a significant association between $\mathrm{CIRCl}$ and WiPO.

Keywords: CIRCI, Mechanical ventilation, Difficult weaning, WiPO

*Correspondence: francois.bagate@aphp.fr

1 AP-HP, DHU A-TVB, Service de Médecine Intensive Réanimation, Centre Hospitalo-Universitaire Henri Mondor, 51, avenue du Mal de Lattre de Tassigny, 94010 Créteil Cedex, France

Full list of author information is available at the end of the article

\section{Introduction}

Critical illness-related corticosteroid insufficiency (CIRCI) was described in intensive care unit (ICU) patients [1], with an impairment of the hypothalamopituitary-adrenal (HPA) axis without anatomical lesions. 
Latest guidelines were unable to reach agreement on a single test that can reliably diagnose CIRCI [2], although delta cortisol (change in baseline cortisol at $60 \mathrm{~min}$ of $<9 \mu \mathrm{g} / \mathrm{dL}$ ) after the corticotropin stimulation test [250$\mu \mathrm{g}$ Adreno CorticoTropic Hormone (ACTH) stimulation test] and a random plasma cortisol of $<10 \mu \mathrm{g} / \mathrm{dL}$ may be used by clinicians. Although the impairment of the HPA axis in critically ill patient is difficult to explore, the stimulation test seems to be useful in establishing a prognostic classification.

Some adrenal profiles derived from corticotropin stimulation test are usually associated with poor outcomes, as alteration of cardiac and vascular functions, prolonged duration of mechanical ventilation (MV) and higher mortality $[3,4]$. The pathophysiology of weaning failure is complex [5], but weaning-induced pulmonary oedema (WiPO) is one of its major established causes $[6,7]$. During the weaning process, the use of spontaneous breathing trial (SBT) is a real stress test [8], which may imply elevation of cortisol level to meet the cardiorespiratory physiological demand. The HPA axis may, therefore, play a major role in the response to the stress induced by ventilator weaning. Because adrenal insufficiency may impair cardiac function [9], we hypothesized that CIRCI may increase WiPO incidence. Conversely, an inadequate adrenal response may be associated with difficult weaning. Studies on the role of adrenal function in weaning failure are scarce [10]. The aims of this study were to evaluate the prevalence of adrenal insufficiency during difficult weaning from $\mathrm{MV}$, and its possible relation with WiPO.

\section{Methods}

\section{Study population}

This ancillary study, planned a priori, was performed in one (Henri Mondor University hospital, Creteil, France) of the four centers participating in a prospective multicenter study assessment of WiPO and weaning-induced myocardial ischemia (WiCI) [11]. Patients screened for enrolment were those intubated for at least $24 \mathrm{~h}$ with ventilator settings allowing to initiate the weaning process $\left[\mathrm{SpO}_{2}>90 \%\right.$ or $\mathrm{PaO}_{2} / \mathrm{FiO}_{2} \geq 150 \mathrm{mmHg}$ with a fraction of inspired oxygen $\left(\mathrm{FiO}_{2}\right) \leq 40 \%$ and a positive end-expiratory pressure (PEEP) $\leq 8 \mathrm{cmH}_{2} \mathrm{O}$ ]. Exclusion criteria included age $<18$ years, decision to withdraw life support, hemodynamic instability with significant doses of vasopressors (dopamine or dobutamine $>10 \mu \mathrm{g} / \mathrm{kg} /$ min, epinephrine or norepinephrine $>0.5 \mathrm{mg} / \mathrm{h}$ ), patient deeply comatose or sedated, extreme temperatures $\left(<36{ }^{\circ} \mathrm{C}\right.$ or $\left.>39{ }^{\circ} \mathrm{C}\right)$ and patients with long-term corticosteroid therapy or under corticosteroid supplementation at time of corticotropin stimulation test. Criteria for SBT failure were respiratory rate $\geq 35$ breaths/minute or increase $\geq 50 \%, \mathrm{SpO}_{2} \leq 90 \%$ or $\mathrm{PaO}_{2} \leq 50 \mathrm{mmHg}$ (with $\mathrm{FiO}_{2} \geq 50 \%$ ), heart rate $\geq 140$ beats/minute, new-onset of supraventricular or ventricular arrhythmia, systolic arterial pressure $>180$ or $<90 \mathrm{mmHg}$, alteration of consciousness, diaphoresis or any signs of respiratory distress [12, 13]. Patients who failed the first SBT were included in the study. A second SBT, consisting of a 2-h T-piece trial [14] was performed within $24 \mathrm{~h}$ after the first SBT in all included patients. Criteria for second SBT failure were the same as for the first SBT. Patients who succeeded the second SBT were extubated.

This study was conducted in accordance with the amended Declaration of Helsinki. The protocol was approved by our institution's local ethics committee (Comité de Protection des Personnes Ile-de-France IX, approval number 10-064). The protocol was considered a component of standard care and the patient's consent was waived. Written and oral information about the study were given to patients or families.

\section{Cortisol assays}

As suggested by the guidelines [2], we used the 250- $\mu$ g

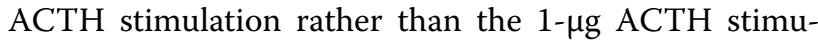
lation test for the diagnosis of adrenal insufficiency for the following reasons. First, the accuracy of the low- and high-dose ACTH tests seems to be comparable [15]. Second, practical modalities of the 1- $\mu \mathrm{g}$ ACTH stimulation test are very complex.

The short corticotropin stimulation test was performed on the morning following the first SBT, by injecting $250 \mathrm{mg}$ of tetracosactrin (Synacthen, Ciba, Reuil-Malmaison, France) intravenously as described previously [16]. The maximal post-stimulation concentration $\left(T_{\max }\right)$ was the highest value between $T_{30}$ and $T_{60}$. The maximal cortisol response $\left(\Delta_{\max }\right)$ was defined as the difference between $T_{\max }$ and $T_{0}$. CIRCI was defined as $T_{0}<10 \mu \mathrm{g} /$ $\mathrm{dL}(276 \mathrm{nmol} / \mathrm{L})$ and $/$ or $\Delta_{\max }<9 \mu \mathrm{g} / \mathrm{dL}(248 \mathrm{nmol} / \mathrm{L})$ [2]. We defined inadequate adrenal reserve as $\Delta_{\max }<9 \mu \mathrm{g} / \mathrm{dL}$, whatever the baseline cortisol $[3,17]$. Additional thresholds for adrenal insufficiency $\left[T_{0}<25 \mu \mathrm{g} / \mathrm{dL}(694 \mathrm{nmol} / \mathrm{L})\right.$ and $\left.\Delta_{\max }<9 \mu \mathrm{g} / \mathrm{dL}(248 \mathrm{nmol} / \mathrm{L})\right]$ were also tested, as proposed by Huang and Lin in a study focusing on ventilator weaning [10].

\section{Weaning-induced pulmonary oedema}

To characterize cardiac function, transthoracic echocardiography was performed just before and at the end of the second SBT, as previously described [18]. Several biomarkers (B-type natriuretic peptide, troponin, protein) were measured during second SBT to assess WiPO. Because there is no non-invasive consensual definition of WiPO, we considered three criteria proposed in the recent literature: (i) echocardiographic signs of increased 
left atrial pressure at the end of the SBT: $E / A$ ratio $>0.95$ and $E / e^{\prime}$ ratio $>8.5$ [19]; (ii) an increase of BNP (absolute change $\geq 48 \mathrm{ng} / \mathrm{L}$ ) or NT-proBNP (absolute change $\geq 21 \mathrm{ng} / \mathrm{L}$ ) concentration during the SBT [20]; and (iii) an increase of protein concentration (relative change $>6 \%$ ) during the SBT [21]. We further combined these criteria into two definitions of WiPO, as follows: a conservative definition (when at least two criteria were fulfilled), and a liberal definition (when at least one criterion was fulfilled) [11]. As per our weaning protocol and current guidelines [13], we performed a cuff leak test in selected patients at high risk of post-extubation stridor; no patient required a preventive or curative steroid treatment for stridor.

\section{Classification of weaning}

Successful weaning was defined as patient alive and not reintubated within the 7 days following extubation, irrespective of the use of non-invasive ventilation [13]. We classified patients into three groups, according to the WIND classification [22], as follows: short weaning (successful weaning or death within 1 day after the first SBT), difficult weaning (successful weaning or death after more than 1 day but in less than 7 days after the first SBT), and prolonged weaning (successful weaning or death after 7 days following the first SBT).

\section{Statistical analysis}

The data were analyzed using the JMP software (version 9; SAS Institute Inc, Cary, NC). Categorical variables were expressed as numbers (percentage) and continuous data as medians (25th-75th percentiles). We used the Chi-squared or Fisher exact test to compare categorical variables between groups and the Student's $T$ test, Mann-Whitney test or Wilcoxon paired test to compare continuous variables, as appropriate. We also used the Kaplan-Meier method to assess the effect of adrenal function on the cumulative probability of successful extubation. Since weaning outcome and death act as competing risks, we designed the present work with a competing risk approach to properly estimate the effect of adrenal function on extubation outcome.

\section{Competing risks analysis}

A competing risk is an event whose occurrence either precludes the occurrence of another event under examination or fundamentally alters the probability of occurrence of this other event [23]. Death is a competing risk for weaning outcome. Indeed, patients are no longer at risk for weaning failure after death. In this context, standard survival methods (Kaplan-Meier method and Cox model) are inappropriate, because they assume that censoring is non-informative and specific competing risk methods need to be considered. We, therefore, used a competing risk model (cumulative incidence function of the Gray model) [24] to properly estimate the effect of adrenal function on weaning outcome (up to day 28 , while considering death as a competing event. The strength of the association between each variable and the outcome was assessed using the sub-hazard ratio associated with the cumulative incidence function estimated using the cmprsk package developed by Gray in the $\mathrm{R}$ software (http://biowww.dfci.harvard.edu/ gray/ cmprsk_2.1-4.tar.gz). Two-sided $p$ values $<0.05$ were considered significant.

\section{Results}

Patient population and ventilator weaning

Among the 145 participants enrolled, a short corticotropin stimulation test could not be completed in 57 patients. Twelve patients were further excluded because of corticosteroid therapy (Fig. 1). Among the 76 patients included in this study, 50 failed (66\%) the second SBT while 26 succeeded (34\%). Among included patients, 19 (25\%) failed extubation. According to the WIND classification [22], weaning was short in 21 patients (28\%), difficult in 33 patients (43\%) and prolonged in 22 patients (29\%). Patient characteristics were similar between simple, difficult and prolonged weaning except for a higher prevalence of heart failure with reduced ejection fraction, septic shock, and ventilator-associated pneumonia before

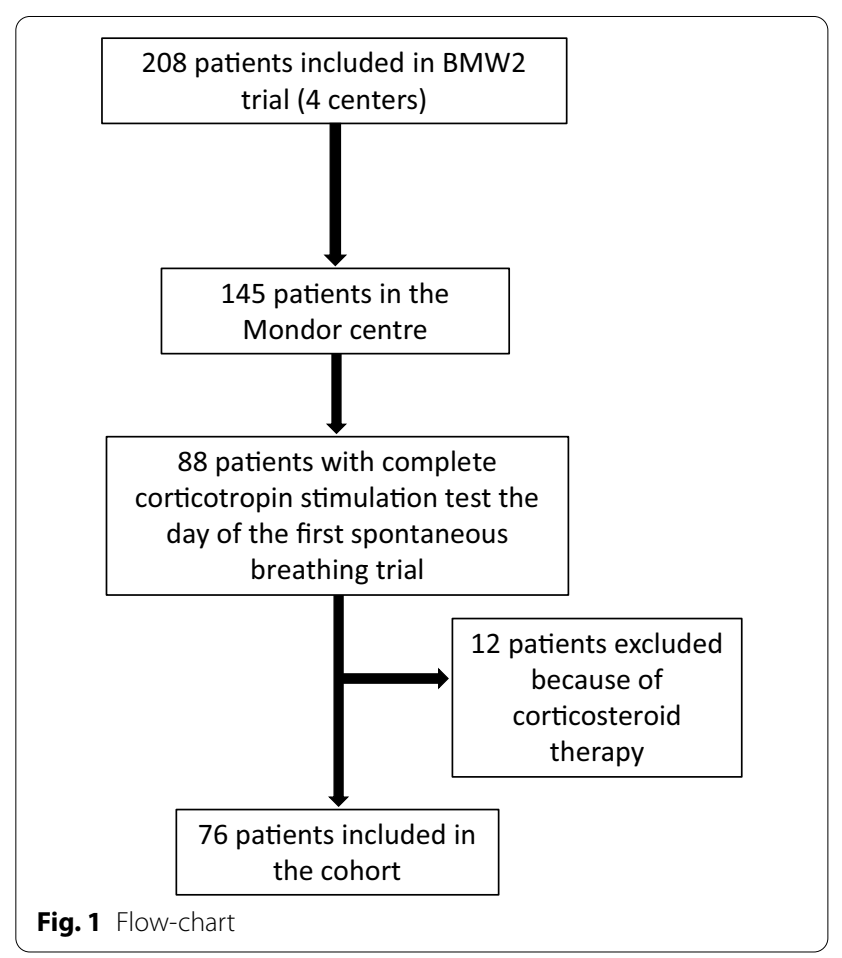


weaning and a longer duration of MV and fluid balance before weaning in patients with prolonged weaning as compared to their counterparts (Table 1). Patients with prolonged weaning exhibited a higher total duration of $\mathrm{MV}$, ICU length of stay, hospital length of stay, and ICU mortality as compared to their counterparts (Table 1).

\section{Adrenal function and ventilator weaning}

Patient characteristics were similar between patients with CIRCI and those without, except for more atrial fibrillation and less restrictive lung disease and obstructive sleep apnea syndrome in the former group (Additional file 1: Table S1). Regarding the outcomes, patients with CIRCI had a higher rate of extubation failure and mortality (Additional file 1: Table S1).

\section{Association between adrenal function and ventilator weaning}

$T_{0}$ and $T_{\max }$ were similar between weaning groups, whereas $\Delta_{\max }$ was lower in patients with prolonged weaning as compared to other groups (Table 2). CIRCI, inadequate adrenal reserve, and adrenal insufficiency (as per Hang and Lin definition) occurred in 25 (33\%), 17 (22\%), and 10 (13\%) patients, respectively (Table 2). Inadequate adrenal reserve and adrenal insufficiency (as per Hang and Lin definition) were more frequent in the prolonged weaning group as compared to other weaning groups, whereas the difference did not reach statistical significance for CIRCI (Table 2). We found no association between adrenal function and WiPO, whatever the definition used for adrenal function and for WiPO (Table 3).

From the Fine and Gray model, the probability of successful extubation during the 28 days following inclusion was significantly lower in patients with altered adrenal function while adjusting for death as a competing event: sub-hazard ratios of $0.54(0.30-0.97), p=0.04,0.24$ (0.08-0.75), $p=0.02$, and $0.25(0.11-0.57), p<0.01$, for CIRCI (Fig. 2a), adrenal insufficiency (as per Hang and Lin definition) (Fig. 2b), and inadequate adrenal reserve (Fig. 2c), respectively. Conversely, the probability of death was significantly higher in patients with altered adrenal function while adjusting for weaning outcome as a competing event: sub-hazard ratios of 3.10 (1.26-7.64), $p=0.01,4.42$ (1.95-10.0), $p<0.001$, and 6.04 (2.46-14.8), $p<0.0001$ for CIRCI (Fig. 2a), adrenal insufficiency (as per Hang and Lin definition) (Fig. 2b), and inadequate adrenal reserve (Fig. 2c), respectively.

\section{Discussion}

We herein report in this cohort of patients who failed their first SBT: (i) a high prevalence of altered adrenal function; and (ii) an association between altered adrenal function and extubation failure, but not with WiPO.

\section{Adrenal insufficiency and corticosteroid therapy during ventilator weaning}

Several studies reported on adrenal insufficiency in patients under prolonged $\mathrm{MV}$, present in about $30-75 \%$ of cases, according to the definitions used [4, 10]. This adrenal insufficiency was associated with a longer weaning period $[4,10]$ and a higher mortality [25]. Moreover, in recent randomized controlled trials assessing the benefit of corticosteroid therapy in septic shock, time to weaning from MV was shorter in the intervention group than the placebo group [26, 27]. However, these studies and ours do not allow to use CIRCI to select for glucocorticoid replacement during ventilator weaning. The usefulness of corticosteroid on weaning from mechanical ventilation could be mediated by hemodynamic improvement and/or inflammation blunting. To date, only one study had specifically evaluated adrenal insufficiency during ventilator weaning [10]. In this cohort of patients under MV for more than $72 \mathrm{~h}$, patients were assessed for adrenal function and those with adrenal insufficiency were randomized to receive $50 \mathrm{mg}$ intravenous hydrocortisone every $6 \mathrm{~h}$ or a placebo. In this trial [10], extubation success was comparable in the adequate adrenal reserve group (88\%) and intervention group (91\%); and these rates were both higher than those of the placebo group (69\%), the latter having a longer weaning duration. The pathophysiological mechanisms underlying these results remain unclear.

\section{Physiologic implications of $\mathrm{CIRCI}$ during weaning}

Based on the known circulatory effect of steroids in septic shock patients [28], the main hypothesis proposed [10], is that stress dose of hydrocortisone may reduce weaning failure by improving hemodynamic stability. Our research group previously showed a close association between adrenal insufficiency and cardiac failure in patients with cardiogenic shock or septic cardiomyopathy [16, 29]. However, we found no association between CIRCI and WiPO in the present cohort. CIRCI may affect weaning outcome via other pathways of stress response. Weaning-induced stress response has been highlighted in different critical care settings including neonatal [30], surgical [31], or medical [6] ICU patient groups. Besides the cardiovascular system, the stress response may involve other major functions of the respiratory or immunologic system. Steroid stress dose administration may improve altered immune response in patients undergoing weaning [28, $32,33]$, but we did not specifically assess ventilatorassociated pneumonia during the weaning phase. 
Table 1 Clinical and biological characteristics of patients according to WIND classification

\begin{tabular}{|c|c|c|c|c|c|}
\hline \multirow[t]{2}{*}{ Variables } & \multirow[t]{2}{*}{ Total $(n=76)$} & \multicolumn{3}{|c|}{ WIND classification } & \multirow[t]{2}{*}{$p$ value } \\
\hline & & Simple $(n=21)$ & Difficult ( $n=33)$ & Prolonged $(n=22)$ & \\
\hline Age (years) & 76 & $61.0( \pm 14.2)$ & $63.4( \pm 13.2)$ & $63.2( \pm 14.3)$ & 0.81 \\
\hline Female gender & 76 & $6(28.6 \%)$ & $13(39.4 \%)$ & $8(36.4 \%)$ & 0.72 \\
\hline Body mass index $\left(\mathrm{kg} / \mathrm{m}^{2}\right)$ & 61 & $26.0(23.5-30.0)$ & $28.6(22.8-35.7)$ & $25.6(22.9-32.5)$ & 0.64 \\
\hline SAPS-II at admission & 76 & $54(34-65)$ & $53(41-71)$ & $50(41-70)$ & 0.43 \\
\hline \multicolumn{6}{|l|}{ Comorbidities } \\
\hline COPD & 76 & $3(14.7 \%)$ & $10(30.3 \%)$ & $7(31.8 \%)$ & 0.34 \\
\hline Restrictive lung disease & 76 & $2(9.5 \%)$ & $6(18.2 \%)$ & $1(4.6 \%)$ & 0.29 \\
\hline Obstructive sleep apnea syndrome & 76 & $6(28.6 \%)$ & $7(21.2 \%)$ & $1(4.6 \%)$ & 0.11 \\
\hline Asthma & 76 & $2(9.5 \%)$ & $0(0 \%)$ & $1(4.6 \%)$ & 0.21 \\
\hline Current smoker & 76 & $9(42.9 \%)$ & $16(48.5 \%)$ & $15(68.2 \%)$ & 0.21 \\
\hline Central nervous system disease & 76 & $2(9.5 \%)$ & $4(12.1 \%)$ & $3(13.6 \%)$ & 0.91 \\
\hline Peripheral neuropathy & 76 & $0(0 \%)$ & $1(3.0 \%)$ & $1(4.6 \%)$ & 0.64 \\
\hline Mental illness & 76 & $2(9.5 \%)$ & $3(9.1 \%)$ & $1(4.6 \%)$ & 0.79 \\
\hline HF with preserved ejection fraction & 76 & $6(28.6 \%)$ & $8(24.2 \%)$ & $3(13.6 \%)$ & 0.47 \\
\hline HF with reduced ejection fraction & 76 & $1(4.8 \%)$ & $3(9.1 \%)$ & $7(31.8 \%)$ & 0.02 \\
\hline Atrial fibrillation & 76 & $2(9.5 \%)$ & $8(24.2 \%)$ & $7(31.8 \%)$ & 0.20 \\
\hline Arterial hypertension & 76 & $12(57.1 \%)$ & $20(60.6 \%)$ & $11(50 \%)$ & 0.74 \\
\hline Valvular heart disease & 76 & $4(19.1 \%)$ & $4(12.1 \%)$ & $3(13.6 \%)$ & 0.77 \\
\hline Coronary artery disease & 76 & $5(23.8 \%)$ & $6(18.2 \%)$ & $6(27.3 \%)$ & 0.72 \\
\hline Pulmonary hypertension & 76 & $1(4.8 \%)$ & $3(9.1 \%)$ & $1(4.6 \%)$ & 0.74 \\
\hline Reason for mechanical ventilation & 76 & & & & 0.46 \\
\hline Coma & & $3(14.7 \%)$ & $4(12.1 \%)$ & $1(4.6 \%)$ & \\
\hline Septic shock & & $3(14.7 \%)$ & $2(6.1 \%)$ & $6(27.3 \%)$ & \\
\hline COPD exacerbation & & $2(9.5 \%)$ & $2(6.1 \%)$ & $1(4.6 \%)$ & \\
\hline Pneumonia & & $3(14.7 \%)$ & $10(30.3 \%)$ & $5(22.7 \%)$ & \\
\hline Cardiogenic pulmonary oedema & & $3(14.7 \%)$ & $2(6.1 \%)$ & $1(4.6 \%)$ & \\
\hline Cardiac arrest & & $3(14.7 \%)$ & $8(24.2 \%)$ & $2(9.1 \%)$ & \\
\hline Surgery & & $1(4.8 \%)$ & $4(12.1 \%)$ & $3(13.6 \%)$ & \\
\hline Others & & $3(14.7 \%)$ & $1(3.0 \%)$ & $3(13.6 \%)$ & \\
\hline \multicolumn{6}{|l|}{ Complications in ICU before weaning } \\
\hline Acute respiratory distress syndrome & 76 & $7(33.3 \%)$ & $12(36.4 \%)$ & $12(54.6 \%)$ & 0.29 \\
\hline Septic shock & 76 & $9(42.9 \%)$ & $12(36.4 \%)$ & $16(72.7 \%)$ & 0.03 \\
\hline Ventilator-associated pneumonia & 76 & $4(19.1 \%)$ & $9(27.3 \%)$ & $13(59.1 \%)$ & 0.01 \\
\hline Atrial fibrillation & 76 & $4(19.1 \%)$ & $9(27.3 \%)$ & $11(50 \%)$ & 0.11 \\
\hline Ventilation duration before first SBT (d) & 76 & $4(3-10)$ & $4(2-11)$ & $13(4-20)$ & $<0.01$ \\
\hline Fluid balance before first SBT $(L)$ & 76 & $3.7(0.9-9.3)$ & $3.5(0.9-9.7)$ & $9.2(2.4-18.5)$ & 0.046 \\
\hline SOFA before weaning & 76 & $3(2-7)$ & $3(2-5)$ & $4(3-6)$ & 0.19 \\
\hline Success of second SBT & 76 & $12(57.1 \%)$ & $11(33.3 \%)$ & $3(13.6 \%)$ & 0.01 \\
\hline \multicolumn{6}{|l|}{ Biological data before weaning } \\
\hline Protidemia (g/L) & 76 & $60.7( \pm 10.0)$ & $60.2( \pm 10.0)$ & $60.8( \pm 8.0)$ & 0.97 \\
\hline Creatinine $(\mu \mathrm{mol} / \mathrm{L})$ & 76 & $87(75-128)$ & $85(58-157)$ & $75(56-123)$ & 0.34 \\
\hline Hemoglobin (g/dL) & 76 & $10.0(8.1-11.0)$ & $9.5(8.3-10.9)$ & $8.6(7.8-10.6)$ & 0.27 \\
\hline White blood count (g/L) & 76 & $12.8(9.1-17.6)$ & $10.1(8.6-14.5)$ & $12.7(8.4-18.2)$ & 0.49 \\
\hline Procalcitonin (mg/L) & 73 & $1.1(0.5-5.0)$ & $0.5(0.2-1.4)$ & $0.6(0.2-1.5)$ & 0.15 \\
\hline \multicolumn{6}{|l|}{ Outcomes } \\
\hline Success extubation & 76 & $21(100 \%)$ & $30(90.9 \%)$ & $6(27.3 \%)$ & $<0.01$ \\
\hline Weaning duration (d) & 76 & $1(1-1)$ & $3(2-5)$ & $17(9-33)$ & $<0.01$ \\
\hline Ventilation duration (d) & 76 & $5(3-7)$ & $7(6-14)$ & $33(20-53)$ & $<0.01$ \\
\hline ICU length of stay (d) & 76 & $7(5-12)$ & $13(9-20)$ & $35(26-58)$ & $<0.01$ \\
\hline Hospital length of stay (d) & 76 & $20(13-30)$ & $23(15-49)$ & $59(32-)$ & $<0.01$ \\
\hline ICU mortality & 76 & $0(0 \%)$ & $3(9.1 \%)$ & $11(50 \%)$ & $<0.01$ \\
\hline
\end{tabular}


Table 1 (continued)

Values are expressed as mean ( \pm SD) or median (IQR) as appropriate

SAPS-II Simplified Acute Physiology Score II, COPD chronic obstructive pulmonary disease, HF heart failure, SBT spontaneous breathing trial, SOFA score Sequential Organ Failure Assessment, ICU intensive care unit

Table 2 Adrenal function of patients according to WIND classification

\begin{tabular}{|c|c|c|c|c|c|}
\hline \multirow[t]{2}{*}{ Variables } & \multirow[t]{2}{*}{ Total $(n=76)$} & \multicolumn{3}{|c|}{ WIND classification } & \multirow[t]{2}{*}{$p$ value } \\
\hline & & Simple $(n=21)$ & Difficult $(n=33)$ & Prolonged $(n=22)$ & \\
\hline$T_{0}(\mathrm{nmol} / \mathrm{L})$ & $655(438-814)$ & $623(373-833)$ & $690(391-849)$ & $615(482-810)$ & 0.84 \\
\hline$T_{\max }(\mathrm{nmol} / \mathrm{L})$ & $977(794-1356)$ & $1055(896-1317)$ & $1039(763-1431)$ & $904(753-1204)$ & 0.36 \\
\hline$\Delta_{\max }(\mathrm{nmol} / \mathrm{L})$ & $429(267-574)$ & $556(429-678)$ & $408(287-638)$ & $261(151-484)$ & $<0.01$ \\
\hline $\mathrm{CIRCl}$ & $25(32.9 \%)$ & $5(23.8 \%)$ & $9(27.3 \%)$ & $11(50 \%)$ & 0.12 \\
\hline Inadequate adrenal reserve & $17(22.4 \%)$ & $2(9.5 \%)$ & $4(12.1 \%)$ & $11(50 \%)$ & $<0.01$ \\
\hline Al (Huang and Lin definition [8]) & $10(13.2 \%)$ & 0 & $1(3.0 \%)$ & $9(40.9 \%)$ & $<0.01$ \\
\hline
\end{tabular}

Values are expressed as mean $( \pm \mathrm{SD})$ or median $(\mathrm{IQR})$ as appropriate

$T_{0}$ : baseline plasma cortisol (before short corticotropin test); $T_{\max }$ : maximal cortisol post-stimulation; $\Delta_{\text {max }}$ : maximal cortisol response; CIRCI: critical illness-related corticosteroid insufficiency $=T_{0}<10 \mu \mathrm{g} / \mathrm{dL}(276 \mathrm{nmol} / \mathrm{L})$ and $/$ or $\Delta_{\max }<9 \mu \mathrm{g} / \mathrm{dL}(248 \mathrm{nmol} / \mathrm{L})$; inadequate adrenal reserve: $\Delta_{\max }<9 \mu \mathrm{g} / \mathrm{dL}(248 \mathrm{nmol} / \mathrm{L})$; Al: adrenal insufficiency (Huang and Lin definition) $=T_{0}<25 \mu \mathrm{g} / \mathrm{dL}(694 \mathrm{nmol} / \mathrm{L})$ and $\Delta_{\max }<9 \mu \mathrm{g} / \mathrm{dL}(248 \mathrm{nmol} / \mathrm{L})$

Table 3 Weaning-induced pulmonary oedema according to adrenal reserve

\begin{tabular}{|c|c|c|c|c|c|c|}
\hline \multirow[t]{3}{*}{ Variables } & \multicolumn{6}{|c|}{ WiPO classification } \\
\hline & \multicolumn{2}{|c|}{ Conservative definition } & \multirow[t]{2}{*}{$p$ value } & \multicolumn{2}{|l|}{ Liberal definition } & \multirow[t]{2}{*}{$p$ value } \\
\hline & Yes $(n=8)$ & No $(n=68)$ & & Yes $(n=44)$ & No $(n=32)$ & \\
\hline$T_{0}(\mathrm{nmol} / \mathrm{L})$ & $833(480-894)$ & $637(438-800)$ & 0.18 & $675(458-875)$ & $611(322-791)$ & 0.17 \\
\hline$T_{0}<276 \mathrm{nmol} / \mathrm{L}$ & $0(0 \%)$ & $9(13.2 \%)$ & 0.58 & $3(6.8 \%)$ & $6(18.8 \%)$ & 0.15 \\
\hline$T_{\max }(\mathrm{nmol} / \mathrm{L})$ & 1136 (896-1439) & $977(781-1325)$ & 0.47 & $1020(896-1414)$ & $893(726-1322)$ & 0.08 \\
\hline$\Delta_{\max }(\mathrm{nmol} / \mathrm{L})$ & $432(201-519)$ & $429(267-614)$ & 0.51 & 466 (279-610) & $404(222-574)$ & 0.49 \\
\hline$\Delta_{\max }<248 \mathrm{nmol} / \mathrm{L}$ & $2(25 \%)$ & $15(22.1 \%)$ & $>0.99$ & $9(20.5 \%)$ & $8(25 \%)$ & 0.64 \\
\hline Al (Huang and Lin def) & $0(0 \%)$ & $10(14.7 \%)$ & 0.59 & $5(11.4 \%)$ & $5(15.6 \%)$ & 0.59 \\
\hline $\mathrm{CIRCl}$ & $2(25 \%)$ & 23 (33.8\%) & $>0.99$ & $12(27.3 \%)$ & 13 (40.6\%) & 0.22 \\
\hline
\end{tabular}

Values are expressed as mean $( \pm \mathrm{SD})$ or median $(\mathrm{IQR})$ as appropriate

WiPO: weaning-induced pulmonary oedema, $T_{0}$ : baseline plasma cortisol (before short corticotropin test), $T_{\max }$ : maximal cortisol post-stimulation, $\Delta_{\text {max }}$ : maximal cortisol response, Al: adrenal insufficiency (Huang and Lin definition) $=T_{0}<25 \mu \mathrm{g} / \mathrm{dL}\left(694 \mathrm{nmol} / \mathrm{L}\right.$ ) and $\Delta_{\max }<9 \mu \mathrm{g} / \mathrm{dL}(248 \mathrm{nmol} / \mathrm{L}), \mathrm{CIRCl}$ : critical illness-related corticosteroid insufficiency $=T_{0}<10 \mu \mathrm{g} / \mathrm{dL}(276 \mathrm{nmol} / \mathrm{L})$ and $/$ or $\Delta_{\max }<9 \mu \mathrm{g} / \mathrm{dL}(248 \mathrm{nmol} / \mathrm{L})$

\section{Strengths and limitations}

Strengths of our study include its prospective design and carefully assessment of WiPO using echocardiography and biomarkers. Limitations of our study include the monocentric setting and the limited sample size, which precluded any robust multivariable analysis of factors associated with extubation failure or CIRCI. In addition, several potential confounding factors can limit the interpretation of these results. Etomidate is a common hypnotic agent, frequently used in rapid sequence intubation in our center and the best-known drug to interfere with cortisol metabolism. A single bolus of etomidate is a major determinant of CIRCI for at least 24-48 $\mathrm{h}[25,34]$. However, the possible influence of this drug on our data is minimized by the systematic use of etomidate in all intubated patients, and the relatively long delay (median of 5 days) between intubation and the initiation of weaning. Moreover, some patients $(n=10,13 \%)$ transiently receiving steroids (not long-term users and not currently under steroids at time of stimulation test) were included and may constitute a limit. However, their adrenal profile $\left(T_{0}\right.$ and $\left.\Delta_{\max }\right)$ did not significantly differ from that of their counterparts. Finally, the more important limitation is probably the interpretation of the corticotropin stimulation test in these critically ill patients during a de-escalation phase. Measure of total plasmatic cortisol may not accurately reflect his real activity, especially 

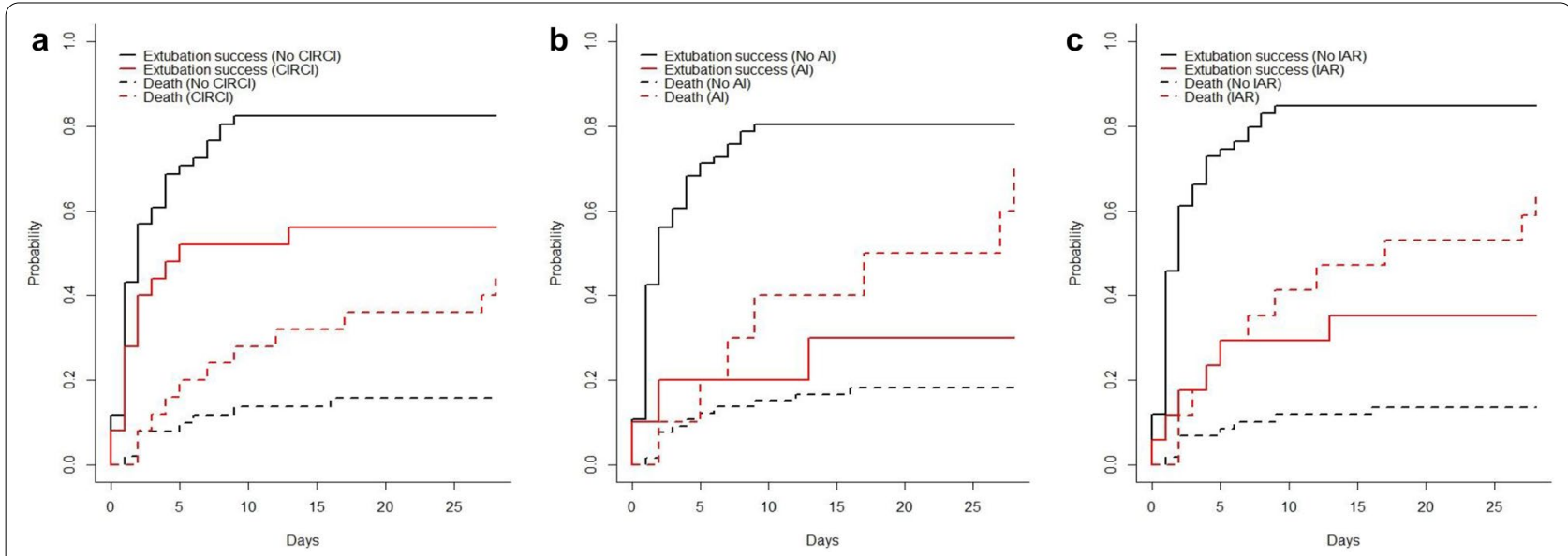

Fig. 2 Cumulative probability of extubation success and death in patients with altered adrenal function (in red) and preserved adrenal function (in black). Time from weaning to extubation success (continuous line), and to death (dashed line) were handled as competing risks. Altered adrenal function was assessed as CIRCI (a), adrenal insufficiency (as per Hang and Lin definition) (b) or inadequate adrenal reserve (c)

in hypoproteinemic patients. Although we found no difference in protidemia level according to adrenal function, free cortisol is probably more suitable [35]. Furthermore, Peeters et al. [36] have recently suggested that corticotropin stimulation test may not provide reliable information on adrenal insufficiency and may not exclude CIRCI in critically ill patients after a prolonged ICU stay (more than 7 days). In the specific population of critically ill patients with difficult weaning, further studies are warranted with plasmatic free cortisol to confirm our results.

\section{Conclusion}

In conclusion, alteration of the HPA axis was common during difficult weaning and associated with poor weaning outcome. We found no association between CIRCI and WiPO. Further studies are needed to scrutinize the role of adrenal function during weaning.

\section{Abbreviations \\ CIRCI: Critical illness-related corticosteroid insufficiency; ICU: Intensive care units; HPA: Hypothalamo-pituitary-adrenal; MV: Mechanical ventilation; WiPO: Weaning-induced pulmonary oedema; SBT: Spontaneous breathing trial; WiCl: Weaning-induced myocardial ischemia; $\mathrm{FiO}_{2}$ : Fraction of inspired oxygen; PEEP: Positive end-expiratory pressure; $T_{\max }$ : Maximal post-stimulation con- centration; $\Delta_{\max }$ : Maximal cortisol response; $T_{0}$ : Baseline cortisol concentration; BNP: B-type natriuretic peptide.}

\section{Supplementary Information}

The online version contains supplementary material available at https://doi. org/10.1186/s13613-021-00852-2.

Additional file 1: Table S1. Clinical and biological characteristics of patients according to $\mathrm{CIRCI}$.

\section{Acknowledgements}

We are very indebted to all physicians and nurses of the Henri Mondor Medical Intensive Care Unit for their help for the care of patients.

\section{Authors' contributions}

$F B$ and $A M D$ designed the study and write the manuscript. FB, AB FT and FB collected the data. KR, NdP, GC designed the study. All authors read and approved the final manuscript.

\section{Funding}

The present study has been conducted without any financial support.

\section{Availability of data and materials}

All data generated and analyzed during the study are included in the published article and can be shared upon request. All authors helped to revise the draft of the manuscript.

\section{Declarations}

\section{Ethics approval and consent to participate}

The protocol was approved by our institution's local ethics committee (Comité de Protection des Personnes Ile-de-France IX, approval number 10-064). The protocol was considered a component of standard care and the patient's consent was waived. Written and oral information about the study was given to patients or families.

\section{Consent for publication}

Not applicable.

\section{Competing interests}

The authors declare that they have no competing interests.

\section{Author details}

${ }^{1}$ AP-HP, DHU A-TVB, Service de Médecine Intensive Réanimation, Centre Hospitalo-Universitaire Henri Mondor, 51, avenue du Mal de Lattre de Tassigny, 94010 Créteil Cedex, France. ${ }^{2}$ Groupe de Recherche Clinique CARMAS, Faculté de Médecine, Université Paris Est Créteil, 94010 Créteil, France. ${ }^{3}$ INSERM U955, Institut Mondor de Recherche Biomédicale, 94010 Créteil, France. ${ }^{4}$ Service de Réanimation Médicale, CHU de Poitiers, Poitiers, France. ${ }^{5}$ INSERM CIC 1402 (ALIVE Group), Université de Poitiers, Poitiers, France.

Received: 17 December 2020 Accepted: 10 April 2021

Published online: 26 April 2021 


\section{References}

1. Marik PE, Pastores SM, Annane D, Meduri GU, Sprung CL, Arlt W, et al. Recommendations for the diagnosis and management of corticosteroid insufficiency in critically ill adult patients: consensus statements from an international task force by the American College of Critical Care Medicine. Crit Care Med. 2008;36:1937-49.

2. Annane D, Pastores SM, Rochwerg B, Arlt W, Balk RA, Beishuizen A, et al. Guidelines for the diagnosis and management of critical illness-related corticosteroid insufficiency $(\mathrm{CIRCl})$ in critically ill patients (Part I): Society of Critical Care Medicine (SCCM) and European Society of Intensive Care Medicine (ESICM) 2017. Intensive Care Med. 2017;43:1751-63.

3. Annane D, Sebille V, Troche G, Raphael JC, Gajdos P, Bellissant E. A 3-level prognostic classification in septic shock based on cortisol levels and cortisol response to corticotropin. JAMA. 2000;283:1038-45.

4. Wu JY, Hsu SC, Ku SC, Ho CC, Yu CJ, Yang PC. Adrenal insufficiency in prolonged critical illness. Crit Care. 2008;12:R65.

5. Heunks LM, van der Hoeven JG. Clinical review: the ABC of weaning failure - a structured approach. Crit Care. 2010;14:245.

6. Lemaire F, Teboul JL, Cinotti L, Giotto G, Abrouk F, Steg G, et al. Acute left ventricular dysfunction during unsuccessful weaning from mechanical ventilation. Anesthesiology. 1988;69:171-9.

7. Teboul JL. Weaning-induced cardiac dysfunction: where are we today? Intensive Care Med. 2014;40:1069-79.

8. Cabello B, Thille AW, Roche-Campo F, Brochard L, Gómez FJ, Mancebo J. Physiological comparison of three spontaneous breathing trials in difficult-to-wean patients. Intensive Care Med. 2010;36:1171-9.

9. Mekontso-Dessap A, Marrache D, Vieillard-Baron A. Images in cardiology: acute adrenal insufficiency complicated by cardiogenic shock. Heart. 2005;91:e31.

10. Huang CJ, Lin HC. Association between adrenal insufficiency and ventilator weaning. Am J Respir Crit Care Med. 2006;173:276-80

11. Bedet A, Tomberli F, Prat G, Bailly P, Kouatchet A, Mortaza S, et al. Myocardial ischemia during ventilator weaning: a prospective multicenter cohort study. Crit Care. 2019;23:321.

12. Boles J-M, Bion J, Connors A, Herridge M, Marsh B, Melot C, et al. Weaning from mechanical ventilation. Eur Respir J. 2007;29:1033-56.

13. Quintard H, I'Her E, Pottecher J, Adnet F, Constantin J-M, De Jong A, et al. Experts' guidelines of intubation and extubation of the ICU patient of French Society of Anaesthesia and Intensive Care Medicine (SFAR) and French-speaking Intensive Care Society (SRLF) : in collaboration with the pediatric Association of French-speaking Anaesthetists and Intensivists (ADARPEF), French-speaking Group of Intensive Care and Paediatric emergencies (GFRUP) and Intensive Care physiotherapy society (SKR). Ann Intensive Care. 2019;9:13.

14. Vallverdú I, Calaf N, Subirana M, Net A, Benito S, Mancebo J. Clinical characteristics, respiratory functional parameters, and outcome of a two-hour T-piece trial in patients weaning from mechanical ventilation. Am J Respir Crit Care Med. 1998;158:1855-62.

15. Ospina NS, Al Nofal A, Bancos I, Javed A, Benkhadra K, Kapoor E, et al. ACTH stimulation tests for the diagnosis of adrenal insufficiency: systematic review and meta-analysis. J Clin Endocrinol Metab. 2016;101:427-34.

16. Bagate F, Lellouche N, Lim P, Moutereau S, Razazi K, Carteaux G, et al. Prognostic value of relative adrenal insufficiency during cardiogenic shock: a prospective cohort study with long-term follow-up. Shock. 2017:47:86-92.

17. Annane D, Bellissant E, Sebille V, Lesieur O, Mathieu B, Raphael JC, et al. Impaired pressor sensitivity to noradrenaline in septic shock patients with and without impaired adrenal function reserve. Br J Clin Pharmacol. 1998;46:589-97.

18. Roche-Campo F, Bedet A, Vivier E, Brochard L, Mekontso DA. Cardiac function during weaning failure: the role of diastolic dysfunction. Ann Intensive Care. 2018:8:2
19. Lamia B, Maizel J, Ochagavia A, Chemla D, Osman D, Richard C, et al. Echocardiographic diagnosis of pulmonary artery occlusion pressure elevation during weaning from mechanical ventilation. Crit Care Med. 2009;37:1696-701.

20. Zapata L, Vera P, Roglan A, Gich I, Ordonez-Llanos J, Betbesé AJ. B-type natriuretic peptides for prediction and diagnosis of weaning failure from cardiac origin. Intensive Care Med. 2011;37:477-85.

21. Anguel N, Monnet X, Osman D, Castelain V, Richard C, Teboul J-L. Increase in plasma protein concentration for diagnosing weaning-induced pulmonary oedema. Intensive Care Med. 2008;34:1231.

22. Beduneau G, Pham T, Schortgen F, Piquilloud L, Zogheib E, Jonas M, et al. Epidemiology of weaning outcome according to a new definition. The WIND study. Am J Respir Crit Care Med. 2017;195:772-83.

23. Gooley TA, Leisenring W, Crowley J, Storer BE. Estimation of failure probabilities in the presence of competing risks: new representations of old estimators. Stat Med. 1999;18:695-706.

24. Fine JP, Gray RJ. A proportional hazards model for the subdistribution of a competing risk. J Am Stat Assoc. 1999;94:496.

25. Malerba G, Romano-Girard F, Cravoisy A, Dousset B, Nace L, Levy B, et al. Risk factors of relative adrenocortical deficiency in intensive care patients needing mechanical ventilation. Intensive Care Med. 2005;31:388-92.

26. Annane D, Renault A, Brun-Buisson C, Megarbane B, Quenot JP, Siami S, et al. Hydrocortisone plus fludrocortisone for adults with septic shock. N Engl J Med. 2018;378:809-18.

27. Venkatesh B, Finfer S, Cohen J, Rajbhandari D, Arabi Y, Bellomo R, et al. Adjunctive glucocorticoid therapy in patients with septic shock. N Engl J Med. 2018:378:797-808

28. Keh D, Boehnke T, Weber-Cartens S, Schulz C, Ahlers O, Bercker S, et al. Immunologic and hemodynamic effects of "low-dose" hydrocortisone in septic shock: a double-blind, randomized, placebo-controlled, crossover study. Am J Respir Crit Care Med. 2003:167:512-20.

29. Bagate F, Razazi K, Boissier F, Seemann A, de Prost N, Carteaux G, et al. Association between relative adrenal insufficiency and septic cardiomyopathy: a preliminary report. Intensive Care Med. 2017;43:1924-6.

30. Quinn MW, de Boer RC, Ansari N, Baumer JH. Stress response and mode of ventilation in preterm infants. Arch Dis Child Fetal Neonatal Ed. 1998;78:F195-8.

31. Calzia E, Koch M, Stahl W, Radermacher P, Brinkmann A. Stress response during weaning after cardiac surgery. Br J Anaesth. 2001;87:490-3.

32. Jackson WL. Adrenal insufficiency and ventilator weaning: additional study is required. Am J Respir Crit Care Med. 2006;173:1176 (author reply 1176).

33. Dimopoulou I. Association between adrenal insufficiency and ventilator weaning. Am J Respir Crit Care Med. 2006;173:934 (author reply 934-5).

34. Vinclair M, Broux C, Faure P, Brun J, Genty C, Jacquot C, et al. Duration of adrenal inhibition following a single dose of etomidate in critically ill patients. Intensive Care Med. 2008:34:714-9.

35. Hamrahian AH, Oseni TS, Arafah BM. Measurements of serum free cortisol in critically ill patients. N Engl J Med. 2004;350:1629-38.

36. Peeters B, Meersseman P, Vander Perre S, Wouters PJ, Vanmarcke D, Debaveye $Y$, et al. Adrenocortical function during prolonged critical illness and beyond: a prospective observational study. Intensive Care Med. 2018;44:1720-9.

\section{Publisher's Note}

Springer Nature remains neutral with regard to jurisdictional claims in published maps and institutional affiliations. 